\title{
A DIVERSIDADE VAI A CRECHE: REFLEXÕES SOBRE A IMPLEMENTAÇÃO DA LEI FEDERAL 10.639/03 NA CRECHE DO MORRO DA QUEIMADA EM FLORIANÓPOLIS
}

\author{
DIVERSITY IN NURSERY \\ SCHOOLS: REFLECTIONS ON \\ THE IMPLEMMENTATION OF \\ FEDERAL LAW N. ${ }^{\circ} 10.639 / 03$ AT THE \\ MORRO DA QUEIMADA NURSERY \\ SCHOOL IN FLORIANÓPOLIS
}

CARDOSO, Paulino de Jesus Francisco ${ }^{1}$ CARDOSO, Cintia ${ }^{2}$

\section{RESUMO}

Este artigo tem por propósito problematizar e discutir as implicações da implementação da Lei Federal 10.639/03 na Creche Morro da Queimada, da Rede Municipal de Ensino de Florianópolis/SC. A partir de um levantamento dos marcos normativos da Educação Infantil e das Diretrizes Curriculares Nacionais para a Educação das Relações Étnico-Raciais e para o Ensino de História e Cultura Afro-Brasileira e Africana (BRASIL, 2005), pretendemos aprofundar nossas análises nos aspectos referentes à prática pedagógica que instigou nosso interesse pela investigação das contradições e ações experienciadas no cotidiano da unidade educativa voltado à promoção da igualdade racial. Para tanto, ancoramos nossa pesquisa em dois aspectos: branquitude normativa e descolonização dos currículos. Diante de tal complexidade, nossas ações serão voltadas para analisar a aplicação da Lei Federal 10.639/03, coadunando com as políticas de promoção da igualdade racial na Rede Municipal de educação infantil de Florianópolis/SC; pretende-se verificar quais os mecanismos utilizados para a construção de uma educação voltada para promoção da igualdade racial. O presente artigo é resultado do projeto extensionista "Suporte às Políticas Públicas de Implementação da Lei Federal 10.639/03 em Santa Catarina", vinculado ao Programa Memorial Antonieta de Barros, do Núcleo de Estudos Afro-Brasileiros da UDESC. Com este estudo pretendemos contribuir para superar as contradições, favorecendo o debate sobre as relações raciais e a implementação da Lei 10.639/2003 na instituição analisada, apontando caminhos para adesão coletiva da proposta e potencializando descobertas de metodologias para aplicação efetiva da Lei nas práticas pedagógicas.

Palavras-chave: Lei 10.639/03. Educação Infantil. Descolonização Curricular. Relações Étnicorraciais. Florianópolis.

\section{ABSTRACT}

This article aims to problematize and discuss the implications of Federal Law n. ${ }^{0} 10.639 / 03$ at the Nursery School Morro da Queimada, which belongs to the Municipal Education System of Florianópolis/SC. The

1 Professor da Universidade do Estado de Santa Catarina (UDESC), Brasil. Doutor em História pela Pontifícia Universidade Católica de São Paulo (PUC-SP). E-mail: paulino.cardoso@gmail.com

2 Professora da Secretaria Municipal de Florianópolis, Brasil. Especialização em Mídias da Educação pelo Instituto Federal de Santa Catarina (IFSC), Brasil. E-mail: cinttiacardoso@gmail.com 
article is based on a survey of Child Education regulations and on the National Guidelines for Education of Racial Ethnic Relations and Afro-Brazilian and African Culture (BRASIL, 2003). The aim is to deepen the analysis concerning the pedagogical practices that motivated the investigation about the contradictions and actions in the routine of a school that aims to promote racial equality. To this end, the research focuses on two aspects: normative whiteness and curricula decolonization. Considering such complexity, the aims are to analyze the application of Federal Law n. ${ }^{0} 10.639 / 03$ articulating it with the policies of equality racial promotion at the Municipal Child Education System in Florianópolis/SC to verify the mechanism used to construct an education aimed at the promotion of racial equality. This article is the result of the outreach project "Support to Public Policies for the Implementation of Federal Law n. ${ }^{0}$ 10.639/03 in Santa Catharina", which is linked to the Program Antonieta de Barros Memorial from the Center of Afro-Brazilian Studies at UDESC (University of the State of Santa Catarina). It is expected that this study can contribute to overcome contradictions, promote the debate about racial relations and the implementation of Federal Law n. ${ }^{0} 10.393 / 03$ in the institution analyzed, point out ways so that there can be a collective adherence to the proposal in addition to the discovery of methodologies for the effective application of the law in pedagogical practices.

Keywords: Law n. ${ }^{0}$ 10.639/03. Child Education. Curricular decolonization. Racial and Ethnic Relations. Florianópolis.

\section{Introdução}

Este artigo tem por propósito problematizar e discutir as implicaçôes da implementação da Lei Federal n. 10.639 em uma creche da Rede Municipal de Ensino de Florianópolis - SC. A partir do levantamento dos marcos normativos da Educação Infantil (BRASIL, 1995), das Diretrizes Curriculares Nacionais para a Educação das Relaçóes Étnico-raciais e para o Ensino de História e Cultura Afro-Brasileira e Africana (BRASIL, 2005) e um levantamento dos documentos oficiais da instituição estudada, pretende-se aprofundar alguns aspectos referentes à prática pedagógica que instigaram nosso interesse na investigação das contradições e ações no espaço escolar.

Diante de tal complexidade, destacamos a importância de analisar a adoção de açóes afirmativas no âmbito educacional que têm influenciado os currículos, coadunando com a compreensão das políticas de promoção da igualdade racial na rede de educação infantil de Florianópolis. Da mesma forma, refletiremos sobre os mecanismos utilizados para a construção de uma educação referente à assunção da valorização da diversidade cultural e da promoção das relaçóes étnicorraciais.

Para além do cumprimento de dispositivos legais, que suscitam questionamentos e indagaçóes sobre o entendimento dos profissionais dessa instituição acerca da importância da história da cultura africana e dos afro-brasileiros, pretendemos contribuir para superar as contradiçóes, favorecendo o debate sobre as relaçóes étnicorraciais e acolhimento real da Lei n. 10.639/2003, apontando caminhos para adesão coletiva da proposta e potencializando descobertas de metodologias para aplicação da lei nas práticas pedagógicas.

Assim, acreditamos que a educação, vista como um caminho próspero para a transformação social, sempre foi sinônimo de lutas da sociedade civil e dos movimentos sociais.

\section{Encontros e desencontros entre os normativos e os documentos da creche}

Diante do exposto, seguimos contextualizando a pesquisa no âmbito da instituição analisada, assim como em sua mantedora: a Prefeitura de Florianópolis. A Creche ${ }^{3}$ analisada localiza-se nas encostas do 3 Texto extraído do Projeto Político Pedagógico da Instituição. 
Maciço do Morro da Cruz, assentamento situado no bairro do José Mendes, próximo à área central da cidade. Ela foi fundada no dia 11 de outubro de 1991 e denominada Creche São Sebastião, a qual era inicialmente mantida pela Associação de Moradores do Morro da Queimada.

A partir de 2001, a Creche começou a ser mantida pela Prefeitura de Florianópolis, sob a responsabilidade da Secretaria Municipal de Educação (SME) com recursos humanos, físicos, estruturais e pedagógicos, e passou a ser denominada "Creche Morro da Queimada”. Hoje, a instituiçáo atende um total de 94 crianças com idades entre 3 e 5 anos, divididas em 5 grupos, por faixa etária. $\mathrm{O}$ quadro de funcionários conta com cinco professores, dez auxiliares de sala, três professores auxiliares de ensino, uma supervisora escolar, uma diretora e dois auxiliares de sala readaptadas.

A comunidade na qual a creche está inserida - Morro da Queimada - é formada por famílias advindas de diferentes regióes do estado de Santa Catarina e de outros, bem como de municípios vizinhos; os migrantes trouxeram consigo suas diferentes histórias de vida e suas etnias, sendo que a maioria é negra. Também, a maior parte dessas famílias é desfavorecida nos aspectos de ordem social e econômica e os pais das crianças que frequentam a Unidade Educativa aqui estudada geralmente possuem pouca escolarização.

Pensando nisso, este texto busca apontar de que forma a Secretaria Municipal de Educação de Florianópolis tem trabalhando com a questão étnico-racial e de que maneira a temática é expressa na política e nos documentos normativos da SME, considerando também como essas diretrizes têm sido interpretadas na creche analisada. Iniciamos, entáo, pela análise dos documentos produzidos para a rede municipal de ensino, tendo os parâmetros nacionais como âncora.

Os documentos da SME de Florianópolis tiveram seu ápice no triênio 2009-2011, período em que são demarcas as maiores mudanças de âmbito nacional. A questáo racial foi posta em movimento desde 1994 com a elaboraçáo da Lei n. 4446/944 , pelo vereador Márcio de Souza que, enquanto pesquisador e militante do movimento negro, atuou em prol da questáo racial. No entanto, embora essa lei tenha sido colocada em movimento nesse período, ela não se constituiu.

Anterior às Leis de Diretrizes e bases - LDB, a referida lei de 1994 dispóe a inclusão do conteúdo "história afro-brasileira" nos currículos das escolas da rede. Assim diz:

Art. $1^{\circ}$ - As escolas da Rede Municipal de Ensino incluirão no programa das disciplinas de Estudos Sociais, História e Geografia o conteúdo "História Afro-Brasileira".

Art. $2^{o}$ - A inclusão deste conteúdo será destinada às crianças da pré-escola e de todas as séries do $1^{\circ}$ grau. (FLORIANOPOLIS, 1994, p. 1).

De acordo com Dias (2011, p. 30) , a Lei Municipal n. 4446/94 foi um avanço do ponto de vista das normativas, porém não se constituiu em execução de práticas pedagógicas que contemplassem a educação das relaçóes étnicorraciais. Os movimentos sociais negros sempre tiveram na educação um dos focos de suas reivindicaçôes, demandando melhoras nas condiçóes de ensino da populaçáo negra e atendimento em regime de igualdade (CARDOSO, 2008)

4 Lei Municipal no 4446/94 - insere a obrigatoriedade das ações desde a pré-escola, conteúdo “história afrobrasileira" nos currículos das escolas da rede.

5 Karina de Araújo Dias (2011).

6 Paulino de Jesus Francisco Cardoso (2008). 
A seguir, elencamos os documentos municipais buscando investigar de que forma eles apresentam a questão racial. São eles:

- Plano Municipal de Educação de Florianópolis/SC (FLORIANÓPOLIS, 2009c);

- Diretrizes Educacionais Pedagógicas para a Educação Infantil (FLORIANÓPOLIS, 2010);

- Orientaçôes Curriculares para Educação Infantil da rede Municipal de Florianópolis/SC (FLORIANÓPOLIS, 2012);

- Currículo da Educação Infantil da Rede Municipal de Ensino de Florianópolis (FLORIANÓPOLIŚ, 2015).

O Plano Municipal de Educação de Florianópolis - SC é subdivido em dezesseis eixos temáticos, os quais contêm diretrizes e metas. Na parte introdutória, o documento traz a afirmação de uma sociedade em transformação: "O homem, as instituições, a sociedade, vivem constante e veloz processo de transformação nas relaçóes sociais estabelecidas, alimentando as desigualdades" (FLORIANÓPOLIS, 2009c). Cada um dos nove eixos traz parâmetros para a educação infantil, destacando que o item diversidade aparece atrelado à cultura.

O Eixo Temático "Educação das Relações" se fundamenta em três princípios norteadores:

- A consciência política e histórica da diversidade e pluralidade da sociedade brasileira;

- A exigência do fortalecimento de identidades plurais e a afirmação de direitos, particularmente, daqueles segmentos historicamente discriminados, como a população afro-brasileira, os povos indígenas e os grupos étnicos minoritários;

- A consecução de açốes educativas de promoção de igualdade étnico-racial e de combate ao racismo e a quaisquer formas de discriminaçáo da sociedade multirracial e pluriétnica, justa e equânime.

Em suas metas, o Plano Municipal de Educação, além de reafirmar a importância de se tomar a diversidade como princípio, estabelece e orienta que os Projetos PolíticosPedagógicos (P. P. P.) apresentem definiçōes, visando ao combate do racismo e das discriminaçôes, com metas para implementar as Diretrizes Nacionais para a Educação das Relaçōes Étnicorraciais.

As Diretrizes Educacionais Pedagógicas para a Educação Infantil (FLORIANÓPOLIS, 2010) apresentam os princípios norteadores do ensino e vinculam o campo cultural à diversidade étnica. Na terceira e última parte do documento, há relatos de vivências de dez unidades de educação infantil de Florianópolis/SC.

Essas diretrizes municipais nos direcionam ao Referencial Curricular Nacional para a Educação Infantil (BRASIL, 1998) que cita um modelo de ação e adesão de projetos educativos voltados para o acolhimento da diversidade. Porém, por se tratar de direcionamentos que têm como objetivo estabelecer parâmetros para o sistema educacional, no que se refere à organização e funcionamento das instituições de Educação Infantil, eles demarcam uma ruptura, se pensarmos no princípio dessas propostas: trazer a identidade cultural a partir de projetos desenvolvidos na Rede Municipal de Educação (RME).

As Orientaçōes Curriculares para Educação Infantil da rede Municipal de Florianópolis/ SC (FLORIANÓPOLIS, 2012) foram concebidas de maneira a servir como um guia de 
cunho educacional para a reflexão sobre os objetivos, os conteúdos e as práticas didáticas dos profissionais que atuam diretamente com crianças de zero a seis anos, respeitando seus estilos pedagógicos e a diversidade cultural brasileira. Esse documento representa um avanço e traz a diversidade, gênero, etnia e cultura como princípios constituintes das relaçôes sociais e educativas; as açóes pedagógicas, com uma abordagem culturalista da diversidade, são orientadas por um olhar que contempla as crianças como sujeitos múltiplos e diversos.

Por fim, o Currículo da Educação Infantil/PMF (FLORIANÓPOLIS, 2015) também representa um avanço por se tratar do primeiro currículo da rede de educação infantil estabelecendo aquilo que deve constar nas açóes pedagógicas. Esse documento parte do princípio da valorização de diferentes origens culturais, sugerindo a inclusão de histórias, contos e lendas que vão ampliando o repertório das crianças para além da tradição europeia. Ele também sugere a ampliação do acervo bibliográfico da unidade escolar através da pesquisa constante das culturas africanas, indígenas, latino-americanas, orientais, entre outras. Se pensarmos em termos de escrita, ao longo do texto observamos uma continuidade das Orientaçóes Curriculares da PMF (FLORIANÓPOLIS, 2015), percebendo que a abordagem parte do mesmo princípio das Orientaçóes e Açóes para a Educação das Relaçóes Étnico-Raciais (BRASIL, 2006).

Diante do exposto, concluímos que os documentos da SME de Florianópolis dialogam com os nacionais, seguindo a lógica de suas estruturas, trabalhando a diversidade de forma mais detalhada, além das relaçóes étnicorraciais, e trazendo a construção de identidades, do respeito, da valorizaçáo e do reconhecimento como elementos imprescindíveis a serem considerados. Constatamos que a inserçáo da diversidade nos documentos é considerada uma das políticas educacionais propostas pela SME citado.

Cabe-nos destacar que nos textos apresentados pela $\mathrm{SME}^{8}$ a questão racial não está silenciada, embora ainda encontrássemos lacunas entre uma normativa e outra. Porém, por valorizar a diversidade como caminho próspero para combater o racismo e o enfrentamento de questóes como o mito da democracia racial, que há muito tempo tenta imprimir uma falsa igualdade entre brancos e negros, esses documentos contribuem para o não silenciamento de tais questôes.

Atribuímos essas modificaçóes à atuação e participação de militantes do movimento negro e pesquisadores/as da área que, através de lutas, debates, embates e proposiçóes, principalmente no âmbito educacional, vêm conquistando mudanças na ação do poder público (RODRIGUES, 2011, p. 12).

No entanto, existe ao longo do processo uma distância entre as leis e a sua aplicação, que é limitada por uma forte relutância, por silenciamentos, tensóes e resistências balizadas pela etiqueta das relaçóes raciais e da cordialidade que, a partir de um discurso universalista, se utiliza do silêncio como estratégia comumente adotada. Assim, concordamos com Munanga (2001, p. 32) quando ele diz que "qualquer proposta de mudança em benefício dos excluídos jamais receberia um apoio unânime, sobretudo quando se trata de uma sociedade racista”.

Resta-nos, nesse momento, continuar indagando sobre a forma com que as políticas propostas pelos documentos municipais estão sendo traduzidas e interpretadas pela Creche Morro da Queimada. É importante ressaltar que a presente pesquisa 
tem uma característica singular por emergir da aproximação da pesquisadora com o Núcleo de Estudos Afro-Brasileiros (NEAB) da Universidade do Estado de Santa Catarina (UDESC). Posteriormente, houve a inclusão da instituição investigada no projeto "Suporte às Políticas Públicas de Implementação da Lei 10.639/03 em Santa Catarina", vinculado ao Programa Memorial Antonieta de Barros, do NEAB/UDESC. Esse projeto objetiva oferecer suporte técnico e pedagógico aos/às gestores/as públicos। as responsáveis pela implementação da Lei Federal no 10.639/03 em âmbito local, estadual e regional.

Desse modo, a finalidade do projeto de extensão está relacionada tanto ao suporte às instituiçôes e educadores(as) quanto à contribuição na formação continuada dos profissionais de educação, apoiando-os e criando condiçóes que proporcionem debates acerca das desigualdades raciais e das formas de implementaçáo das leis e diretrizes. Visase também procurar maneiras de efetivar essas políticas na escola e articulá-las com os conteúdos lecionados pelo(a) educador(a), chegando à ponta do sistema - o cháo da escola -, no que diz respeito à inserção da educação das relações étnicorraciais nos currículos e práticas escolares, como respaldado pela Lei Federal n. 10.639/03.

Falando em "chão da escola", partem daí nossas primeiras indagaçôes para alcançar os objetivos que nasceram da observação participante, necessitando sensibilizar nosso olhar para a compreensão do espaço e significados postos no ambiente. Por isso, foi necessário ampliar a atençáo sobre o que parecia estar evidente e buscar uma observação atenta e cuidadosa, mobilizando nossos conhecimentos com elementos ínfimos, com os quais estamos envolvidos (GRAUE; WALSH, 2003, p. 118).

Buscou-se aguçar o olhar para os diferentes ângulos a serem conhecidos dentro um mesmo local, já que cada olhar nos fornecia dados essenciais para a construção da descrição da realidade a ser conhecida; o trabalho de observaçáo possibilitou uma maior interação com o campo e com a comunidade escolar. Segundo Geertz (1989), os estudos etnográficos exigem um esforço de "interpretaçáo" e, como salienta o autor, "fazer etnografia é como tentar ler um manuscrito estranho, desbotado, cheio de elipses, incoerências, emendas suspeitas e comentários tendenciosos" (GEERTZ, 1989, p. 20).

$\mathrm{O}$ documento que sistematiza as propostas e concepçóes das unidades educativas da Prefeitura Municipal de Florianópolis é orientado com base na Resolução n. 003/200910 (FLORIANÓPOLIS, 2009b) e no Conselho Municipal de Educação, Resolução n. 01/2009 (FLORIANÓPOLIS, 2009a), que fixam normas para a Educaçáo Infantil no âmbito do Sistema Municipal de Ensino do Município de Florianópolis/SC. Ao analisar o texto, fica explícito que a creche aqui analisada se trata de uma unidade escolar que tem clareza da multiplicidade de indivíduos que abriga. "Aqui dividem o espaço", negros, brancos, pardos, evangélicos, espíritas, católicos, umbandistas, dentre outros, demonstrando a riqueza de experiências manifestas nesse meio. As diferenças referentes à cor, raça, etnia e crédulo abrem a creche para um espaço de crítica e diversidade, elementos que constituem crescimento e cidadania.

No entanto, o documento não apresenta dados da origem das famílias da comunidade escolar ou como elas se autodeclaram, assim como não fundamenta nem utiliza aportes teóricos sobre como aborda e trabalha com a diversidade. Infelizmente, 
também não contempla uma educação voltada para luta antirracista, embora palavras como diversidade, identidade, religiosidade sejam citadas ao longo do documento. Assim, interpretamos esses termos como palavras-padrão para a produção de um discurso universal, visto que os documentos normativos nacionais náo aparecem ao longo do texto.

Assim como nos fundamentos norteadores, a adesão de projetos coletivos, como o "Projeto Étnico Racial", surge numa tentativa de visibilizar a questão, porém não traz nenhum possível princípio para concretizá-la na prática, revelando um silêncio que envolve a questáo racial de trabalhos que consideram a creche e relaçóes raciais. $\mathrm{Na}$ proposta pedagógica inexistem metas e açôes como prioridades, visto que no diagnóstico escolar não se explicita que as relaçóes entre crianças negras e brancas na educaçáo infantil possivelmente são e serão marcadas por conflitos, balizadas por preconceitos e estereótipos, inferiorizando determinadas culturas em relação às outras. Da mesma forma, o documento não utiliza dados empíricos para caracterizar a comunidade atendida, não apresentando articulação entre os Estudos Sociais da Infância e os Estudos sobre Relaçôes Étnicorraciais no Brasil.

Nesse modelo de elaboração do P. P. P., deparamo-nos com contradiçóes que mostram que a discussão sobre a Lei n. 10.639 não está posta. A própria concepção de educação infantil abordada no projeto da escola por si só traz a compreensão e o reconhecimento da infância e da criança, mas ao longo do documento não percebemos essas singularidades expressas nem referenciadas na sua estruturação. Os conceitos estão dispostos de uma forma muito ampla, não apontando caminho para trabalhar e incluir a Lei n. 10.639 como uma ação pedagógica dentro da instituição.

A partir daí, encontramos um dos primeiros entraves: como implementar algo que não é visibilizado nos documentos oficiais presentes na instituição? $\mathrm{O}$ mesmo se percebe no Plano de gestáo, em que "o documento explicita um discurso universal desconsiderando os aspectos de raça, etnia, classe social e gênero". O discurso da gestão democrática aparece ao longo do documento, porém oculta o papel do gestor como um dos protagonistas e executores das políticas públicas do Estado. Esse documento demonstra uma ausência no que tange às questóes sobre a diversidade e a consciência clara da nova perspectiva de ressignificação do papel da gestão diante dos novos paradigmas. No Plano de Metas Anual inexiste qualquer ação voltada para a superação das desigualdades dentro da unidade educativa, não contemplando uma educação voltada para luta antirracista e revelando um silêncio em relação à questão racial.

Seguindo na investigação, a partir de relatos informais ocorridos por meio de diálogos com os professores/as, com a gestora e a supervisora da instituiçãa estudada, complementamos os dados e as observaçóes realizadas durante a pesquisa. A partir dos relatos das/os profissionais percebemos que o desejo de implementar a Lei Federal, 10.639/03 não vem sendo silenciado e, muito pelo contrário, vem borbulhando nos encontros e diálogos informais.

Todavia, a busca até então foi por propostas prontas que náo estavam articuladas com as reflexóes pautadas nos documentos norteadores e, na maioria das situaçóes, com reflexóes sem objetivos claros de onde se almejava chegar. Analisando a formação continuada disponibilizada pelo município de Florianópolis/SC, foi possível constatar que capacitação complementar voltada para a questão das relaçóes étnicorraciais na PMF ocorre na modalidade de formaçáo em serviço, em encontros gerais, por meio de seminários, palestras e cursos. Embora a formação docente para as questóes raciais tenha se 
intensificado na SME no ano de 2009, muitos profissionais náo foram contemplados com isso, pois em alguns momentos esse processo se concretiza através de representatividade.

De acordo com Silva (2010), o uso do recurso de professores/as multiplicadores/as levanta algumas implicaçóes, principalmente, a respeito das dificuldades de socializaçáo das discussóes, problematizaçốes e materiais dispostos durante o curso para os/as demais integrantes das unidades. Esse cenário vem ao encontro dos resultados de pesquisas (DIAS, 2011; SILVA, 2010) que apontam que, embora existam propostas que busquem contemplar a temática, as açóes sấo proporcionalmente pequenas considerando a gama total de formaçóes e demais atuaçóes que são promovidas pelas Secretarias de Educação. Por isso, a relevância da inclusão de todos os sujeitos nos ambientes de formaçáo.

Nas falas dos profissionais, a modalidade de formaçáo em serviço é o que tem mais contribuído para as suas práticas pedagógicas, pois abrange todos os profissionais, propiciando debates que váo ao encontro das necessidades cotidianas e acontecimentos vividos. Quando questionados sobre como lidam com as questóes de racismo no cotidiano, as respostas dos profissionais de educaçáo muitas vezes são permeadas pelo mito da igualdade racial. Com isso muitas/os professores silenciam e reproduzem açóes de preconceito racial, reforçando desigualdades.

A resultante da nossa pesquisa aponta para a necessidade de uma reestruturaçáo dos moldes atuais da visão de educação da grande maioria dos profissionais. Nesse sentindo, a investigação que está sendo desenvolvida na Creche Morro da Queimada segue apontando novos caminhos. 
Referências

BRASIL. Ministério da Educação. Diretrizes Curriculares Nacionais para a Educação das Relações Étnico-raciais e para o Ensino de História e Cultura Afro Brasileira e Africana. Brasília: MEC, 2005.

. Educação Infantil: bibliografia anotada. Brasília: MEC, 1995.

. Lei de Diretrizes e Bases da Educação Nacional. Brasília: MEC, 1996.

SECAD, 2006.

Orientações e ações para a educação das relações étnico-raciais. Brasília:

Referencial Curricular Nacional para a Educação Infantil: Introdução, v. 1. Brasília: MEC, 1998.

CARDOSO, Paulino de Jesus Francisco. Notas sobre o movimento negro no Brasil. In: SPONCHIADO, Inês Justina; SILVA, Vania Beatriz Monteiro (Orgs.). Contribuiç̧ões para a Educação das Relações Étnico-Raciais. Florianópolis: Letras Contemporâneas, 2008.

DIAS, Karina Araújo. Formação Continuada para Diversidade Étnico-Racial: Desafios Pedagógicos no Campo das Ações Afirmativas na Rede Municipal de Ensino de Florianópolis. 2011. 285 f. Dissertação (Mestrado em Educação). Florianópolis: Universidade Federal de Santa Catarina, 2011.

FLORIANÓPOLIS. Câmara Municipal de Vereadores. Lei n. 4446 de 05 de julho de 1994. Florianópolis, 1994.

FLORIANÓPOLIS. Prefeitura Municipal. Conselho Municipal de Educação. Resolução n. 01/2009. Florianópolis, SC: SME, 2009a.

. Resolução n. 03/2009. Florianópolis, SC: SME, 2009 b.

Plano Municipal de Educação de Florianópolis. Florianópolis, SC: SME, 2009c.

Orientações Curriculares para Educação Infantil da rede Municipal de Florianópolis/SC. Florianópolis, SC: SME, 2012.

FLORIANÓPOLIS. Prefeitura Municipal. Secretaria Municipal de Educação. Diretrizes educacionais pedagógicas para educação infantil. Florianópolis: Prelo, 2010.

. Currículo da Educação Infantil da Rede Municipal de Ensino de Florianópolis. Florianópolis: SME, 2015.

GEERTZ, Clifford. A interpretação das culturas. Rio de Janeiro: Zahar, 1989.

GRAUE, M. Elizabeth; WALSH, Daniel J. Investigação etnográfica com crianças: teorias, métodos e ética. Lisboa: Fundação Calouste Gulbenkian, 2003. 
MUNANGA. Kabengele. Políticas de ação afirmativa em benefício da população negra no Brasil: um ponto de vista em defesa de cotas. Revista Sociedade e Cultura, v. 4, n. 2, p. 31-43, jul./dez. 2001.

RODRIGUES, Tatiane Consentino. A ascensão da diversidade nas políticas educacionais contemporâneas. 2011. 234 f. Tese (Doutorado em Educação). São Carlos: Universidade Federal de São Carlos, 2011.

SILVA, Kátia Vicente da. A Implementação da Lei 10.639/03 no Município de São João de Meriti: Limites e Possibilidades. 2010. 114 f. Dissertação (Mestrado em Educação). Rio de Janeiro: Universidade Federal do Estado do Rio de Janeiro, 2010. 